Nat Rev Genet. 2012 October ; 13(10): 693-704. doi:10.1038/nrg3246.

\title{
The telomere syndromes
}

\author{
Mary Armanios ${ }^{1,2}$ and Elizabeth H. Blackburn ${ }^{3}$ \\ ${ }^{1}$ Department of Oncology, Sidney Kimmel Comprehensive Cancer Center, Johns Hopkins \\ University School of Medicine. \\ ${ }^{2}$ McKusick-Nathans Institute of Genetic Medicine, Johns Hopkins University School of Medicine, \\ 1650 Orleans Street, CRB Room 186, Baltimore, Maryland 21287, USA. \\ ${ }^{3}$ Department of Biochemistry and Biophysics, University of California, San Francisco, 600 16th \\ Street, Room S312F, Campus BOX 2200, San Francisco, California 94158-92517, USA.
}

\begin{abstract}
There has been mounting evidence of a causal role for telomere dysfunction in a number of degenerative disorders. Their manifestations encompass common disease states such as idiopathic pulmonary fibrosis and bone marrow failure. Although these disorders seem to be clinically diverse, collectively they comprise a single syndrome spectrum defined by the short telomere defect. Here we review the manifestations and unique genetics of telomere syndromes. We also discuss their underlying molecular mechanisms and significance for understanding common agerelated disease processes.
\end{abstract}

Telomeres are DNA-protein structures that protect chromosome ends from degradation and fusion ${ }^{1}$. They are therefore essential for the maintenance of genomic integrity. Several observations have established the role of telomeres in cellular ageing. Because the replication machinery cannot fully copy to DNA ends, telomeres shorten progressively with cell division, eventually triggering senescence ${ }^{2}$. This observation has raised the idea that the length of telomeres may serve as a 'molecular clock' and that the accumulation of short telomeres with age in humans may contribute to age-dependent processes ${ }^{3}$. A compensatory mechanism, primarily the enzyme telomerase, in some settings adds back additional telomeric $\mathrm{DNA}^{4,5}$. This Review highlights how recent discoveries in human genetics have synergized with the field of telomere biology to unequivocally establish a causal role for telomere dysfunction in several specific, common and recognizable disease contexts.

The field of telomere research started with a focus on fundamental cellular mechanisms and in simple model organisms (reviewed in Ref. 6). Observations in the 1990s linked telomere biology to cancer, which was the first human disease in which telomeres were thought to have a role. Telomerase activity was found to be upregulated in most cancers ${ }^{7}$, and since then telomerase has been pursued as a target in cancer treatment ${ }^{8}$. In the past decade, discoveries in the area of human genetics have defined a new and emerging field; its findings establish a clear role for telomere dysfunction in diverse degenerative disease states. This field was sparked around the turn of the twenty-first century when the genetic basis of a rare disorder known as dyskeratosis congenita was elucidated. Unbiased positional cloning techniques identified mutations in the dyskeratosis congenita 1 (DKCI) gene, which

(C) 2012 Macmillan Publishers Limited. All rights reserved

Correspondence M.A. marmani1@jhmi.edu.

Competing interests statement

The authors declare competing financial interests: see Web version for details. 
encodes a conserved protein called dyskerin, but initially the function of dyskerin was not known ${ }^{9}$. Insights into telomerase biochemistry then revealed that it was as an essential component of the telomerase enzyme ${ }^{10,11}$. This early work has since led the path to the identification of a number of mutated telomerase and telomere genes using both unbiased and candidate gene approaches. During the past 5 years, the range of diseases affected by telomere length disequilibrium has been greatly extended and now encompasses prevalent disorders that have previously been poorly understood. Among these, the lung disease idiopathic pulmonary fibrosis (IPF) - best known until recently by its 'idiopathic' adjective - is the most common manifestation of telomere-mediated disease ${ }^{12}$. The cumulative evidence that we review here highlights a group of diverse disorders that share the molecular defect of short telomere length. Because of their overlapping clinical features, it has been proposed to consider them as a single syndrome spectrum ${ }^{13}$, and here we refer to them as 'the telomere syndromes.' The telomere syndromes are highly relevant for understanding age-related disease because the short telomere defect that they share is acquired with age. Moreover, as we will discuss, they probably represent the most prevalent monogenic premature ageing disorders.

In this Review, we aim to highlight the clinical spectrum of the telomere syndromes and present a model within which to understand their diverse clinical manifestations. Because, as we discuss, telomere length is heritable, the unique inheritance patterns that distinguish these syndromes from other Mendelian disorders are also discussed. Finally, we examine how telomere biology provides insights into disease mechanisms in several important contexts in which novel therapeutic paradigms are needed.

\section{Telomeres and telomerase}

\section{Telomere structure}

In humans and other vertebrates, the telomeric DNA sequence is a tract of tandem repeats of the six-nucleotide unit sequence TTAGGG ${ }^{14,15}$. These sequences extend for thousands of bases at chromosome ends, averaging $10 \mathrm{~kb}$ in a newborn human's cord blood ${ }^{16}$. Telomere DNA is bound by a specialized group of protective proteins collectively called shelterin ${ }^{17}$. The human shelterin complex includes six proteins: telomere repeat binding factor 1 (TRF1), TRF2, repressor/activator protein 1 (RAP1), TRF1-interacting nuclear protein 2 (TIN2), TIN2-interacting protein 1 (TPP1) and protection of telomeres 1 (POT1) (Fig. 1). The combination of intact shelterin components and a telomere of sufficiently long tract length is essential to protect a chromosome end from eliciting DNA damage responses, deleterious degradation or participation in genomedestabilizing recombination or fusion events (reviewed in Ref. 18). Another complex that is relevant to the disease processes discussed below, known as CST, comprises three proteins - conserved telomere protection component 1 (CTC1), suppressor of cdc thirteen 1 (STN1) and telomeric pathway with STN1 (TEN1) - and is also found at human telomeres ${ }^{19,20}$ (Fig. 1). CST binds singlestranded DNA, and CTC1 is thought to function in telomere and non-telomere laggingstrand synthesis ${ }^{21,22}$. Although the telomere-protective roles of budding yeast CST are extensively characterized, the functional specificity of CST at mammalian telomeres remains unclear, and CST may have more general roles in DNA replication ${ }^{21,22}$. As described below, mutations in genes that code for some of these telomere proteins have recently been shown to cause a subset of telomere syndromes.

\section{Telomerase structure}

Telomerase is the specialized DNA polymerase that synthesizes new telomere sequences onto chromosome ends ${ }^{4,5,23}$. Telomerase has two conserved components that carry out the function of telomere repeat addition: the core telomerase protein, TERT, which contains the 
telomerase reverse transcriptase domain, and an essential RNA component, TR (also known as TERC), which complexes with TERT and provides the template for telomeric sequence synthesis ${ }^{23-25}$. The human telomerase holoenzyme is thought to assemble in the cajal body, where TERT and TR form a ribonucleoprotein enzyme complex ${ }^{26}$. Although TERT and TR are sufficient to generate enzyme activity in vitro, telomerase relies on other proteins for its assembly, trafficking and regulation ${ }^{26,27}$. The best-characterized mammalian telomerase accessory component is the dyskerin protein ${ }^{11}$. Dyskerin forms a core complex with three smaller proteins NHP2, NOP10 and GAR1 (Ref. 28). Dyskerin binds to an H/ ACA box RNA structural motif within TR (as well as small nucleolar RNAs) and is essential for TR stability and telomerase function in vivo ${ }^{10,11,29}$ (Fig. 1). Another protein, the telomerase Cajal body protein 1 (TCAB1), binds TR and regulates its trafficking ${ }^{30,31}$ (Fig. 1). As described below, mutations in the genes that encode the essential telomerase components - namely, TERT, TR and $D K C 1$ - are a common cause of human telomere syndromes.

\section{Elongation of telomeres by telomerase is tightly regulated}

Telomere elongation is cell-cycle-regulated; telomerase elongates telomeric DNA by adding telomere repeats during $\mathrm{S}$ phase and into $\mathrm{M}$ phase $\mathrm{p}^{32,33}$. Responding to cis-regulatory mechanisms mediated through the telomere DNA-protein complex, telomerase preferentially elongates the shortest telomeres, so only a subset of telomeres may be elongated in any cell cycle ${ }^{34}$. The extent of telomere elongation is highly sensitive to telomerase levels, as is evident by the haploinsufficiency for genes encoding telomerase components that is seen in yeast, mouse and human cells ${ }^{35-41}$. Even at wild-type levels, telomerase generally elongates only a few telomeres in any given cell cycle or generation $^{34,36}$. This may be due to unbalanced stoichiometry between telomerase and its substrates, as well as to other telomerase-independent processes. Even in somatic human cells that are naturally enriched for telomerase activity, such as haematopoietic stem cells (HSCs), telomeres typically become shorter with each cell division and with age ${ }^{42,43}$. In human male germ cells, telomere lengths remain stable or even elongate with age ${ }^{3}$. The mechanisms by which telomeres are maintained in germ cell lineages, which are enriched for telomerase ${ }^{7}$, are not fully understood.

The limitation on the telomerase synthesis reaction on human telomeres favours telomere shortening as a general default state and means that telomere shortening generally accompanies cell proliferation. The constitutional telomere length in humans and mice is likely to be set early in embryonic development, when telomerase activity is transiently upregulated $^{44}$.

Some biological rationales that underlie the tight regulation of telomerase levels include the possibility that short telomeres have a protective role as an innate tumour suppressive mechanism in long-lived, multicellular organisms by limiting the replicative potential of cells ${ }^{45}$. This idea is consistent with the fact that telomerase activity is upregulated in most human cancers, which probably contributes to sustaining their immortality ${ }^{7}$. Limiting telomerase levels may also prevent unwanted telomere addition at DNA double-strand-break sites, which could happen if telomerase competes with appropriate DNA repair mechanisms ${ }^{46,47}$. Another compatible explanation may be that the telomere 'clock mechanism' is under evolutionary selection because by possibly limiting organismal lifespan, it ensures a constant infusion of a diverse genetic pool into the population of some species. 


\section{Telomere length measurement}

To understand the links between genetic defects in telomere maintenance, telomere length and disease pathogenesis, it is important to be able to quantify telomere length. Appreciation for a unified genetic mechanism for a number of syndromes discussed below has been in part due to advances in telomere length measurement and in assembling the normal ranges. Measuring telomere length has unique considerations because in a given cell there are many telomeres, and each telomere has a unique length. A complete telomere length profile therefore reflects the mean telomere length as well as the length distribution within a given cell type (for example, of the 92 telomeres in a human interphase cell). Studies in mice and yeast have shown that it is not the average but the shortest telomeres that determine cell responses, suggesting that only one, or a few, overtly short telomeres trigger the DNA damage response and the consequent checkpoint cascade $34,48,49$. For human fibroblasts, a threshold of five dysfunctional short telomeres seems to be needed to trigger a senescence response in vitro ${ }^{50}$. The shortest telomeres hence have a genetically dominant role in determining cellular phenotypes. In human studies, measuring the shortest telomeres in a population of cells is not readily feasible for practical reasons, and the mean telomere length in leukocytes or leukocyte subsets is typically measured instead. When examining telomere measurements within a mixed cell population, it is important to note that this is a surrogate marker of the mean in a heterogeneous cell population and that telomere length is mosaic, reflecting the telomere length regulation and replicative history of each cell type ${ }^{51,52}$. Methods that are commonly used to measure telomere length include restriction fragment analysis, fluorescence in situ hybridization and PCR-based techniques. These methods are reviewed in detail elsewhere ${ }^{53}$. In the monogenic syndromes discussed below, telomere length measurement on peripheral blood lymphocytes using fluorescence in situ hybridization and flow cytometry is a useful diagnostic tool in certain clinical settings ${ }^{54-57}$.

\section{The monogenic telomere disorders}

Several discoveries made during the past decade have underscored the importance of telomere length maintenance in human disease. The initial discoveries primarily came from studies of rare monogenic disorders of childhood but have more recently come to encompass common disorders that manifest well into adulthood. Together they can be appreciated as a single spectrum caused by defects in telomere maintenance. Synergistic with these genetic discoveries has been a deepening understanding of telomerase and telomere biology that has helped to define their underlying pathophysiology. In this section, we highlight the clinical manifestations as well as the unique genetics of the monogenic telomere syndromes.

Although the Mendelian telomere disorders have diverse clinical presentations, they share an underlying defect of short telomere length. Their grouping together as a syndrome spectrum is crucial for clinical decisions because the short telomere defect in affected individuals is present in germ cells and thus simultaneously affects multiple organs even when one disease presentation predominates. The mutant telomere genes, their prevalence in disease contexts and the genetic mechanisms by which mutant genes cause telomere shortening are summarized in Table 1.

\section{Childhood-onset telomere disorders}

Dyskeratosis congenita was the first disorder to be linked to a mutant telomere gene $e^{9,11,38}$. Its incidence is thought to be rare, estimated at 1 in 1 million individuals. Dyskeratosis congenita is classically defined by mucocutaneous features: skin hyperpigmentation, oral leukoplakia and nail dystrophy 58 . The primary causes of mortality are bone marrow failure, pulmonary fibrosis and cancer ${ }^{58}$. The underlying biology of the cancer-prone state in dyskeratosis congenita is discussed later in this Review. Although affected individuals do 
not generally have overt progeroid features, they develop progressive and apparently irreversible organ failure. The organ failure patterns resemble many features of age-related disease ${ }^{13}$. In most cases $(80 \%)$ of dyskeratosis congenita, the organ failure occurs first in the bone marrow in aplastic anaemia ${ }^{58,59}$.

Dyskeratosis congenita is characterized by the short telomere defect ${ }^{11,38,55}$. However, its genetic basis and mode of inheritance vary, and X-chromosome-linked-recessive, autosomal-dominant, autosomal-recessive and de novo cases have all been described ${ }^{58,59}$. Eight mutant genes have been identified in dyskeratosis congenita $9,38,39,60-64$, and all of them encode telomerase or telomere protein components (summarized in Table 1). Mutations in the $\mathrm{X}$ chromosome $D K C 1$ gene, which encodes dyskerin, and TRF1-interacting nuclear factor 2 (TINF2), which encodes the shelterin component TIN2, are the most commonly identifiable in classic dyskeratosis congenita ${ }^{59}$. Heterozygous TINF2 mutations usually manifest in the first decade of life as severe de novo dyskeratosis congenita cases and are thus only rarely transmitted in an autosomal-dominant fashion ${ }^{62}$. Mutations in $T E R T$ and $T R$ account for less than $10 \%$ of autosomal-dominant dyskeratosis congenita $^{38,39}$. Altogether, mutations in four genes - DKC1, TINF2, TERT and TR account for most dyskeratosis congenita cases with an identifiable genetic defect. Mutations in the telomerase accessory proteins NHP2 (Ref. 60), NOP1O (Ref. 61) and TCAB1 (Ref. 63 ) have been reported in rare autosomal-recessive families. A recent case report identified biallelic mutations in $C T C 1$ in a patient with dyskeratosis congenita ${ }^{64}$. In $\sim 40 \%$ of cases, dyskeratosis congenita remains genetically uncharacterized.

Two other rare disorders with onset in infancy have been linked to severe telomere dysfunction and mutant telomerase and telomere genes (Table 1). Hoyeraal-Hreidarsson syndrome is characterized by developmental delay, immunodeficiency and cerebellar hypoplasia ${ }^{58}$. Revesz syndrome is characterized by bilateral exudative ret inopathy ${ }^{62}$. These more severe telomere syndromes are associated with extensive telomere shortening and often first present with complications related to immunodeficiency, and bone marrow failure develops later in life, similarly to dyskeratosis congenita ${ }^{65}$ (Fig. 2). Recently, biallelic mutations in $C T C 1$ were identified in patients with Coats plus syndrome, which is characterized in part by exudative retinopathy and intracranial calcifications ${ }^{66,67}$. Both of these features can be seen in Hoyeraal-Hreidarsson and Revesz syndromes. CTC1 mutation carriers have a short telomere length relative to age-matched controls, but whether this is a pure telomere disorder or a compound defect that is also related to non-telomere functions of CTC1 remains to be fully determined ${ }^{22,66}$. On the basis of their overlapping clinical findings, Hoyeraal-Hreidarsson and Revesz syndromes (and probably Coats plus syndrome) represent the same spectrum of disease because retinopathy, intracranial calcifications and bone marrow abnormalities can be seen in all three disorders and occur in the setting of very short telomere length. The differing nomenclature of these disorders probably reflects in part the clinical complications that were first documented before elucidation of the shared underlying telomere defect.

\section{Adult-onset manifestations of telomere-mediated disease}

Telomere disorders most commonly manifest as adult-onset disease and as a consequence of germline TERT or TR loss-of-function mutations ${ }^{13}$. The frequency of these mutations is highest in individuals with the progressive disorder IPF, which accounts for $8-15 \%$ of familial and $1-3 \%$ of sporadic cases ${ }^{54,56,68,69}$. In families, pulmonary fibrosis displays autosomal-dominant inheritance with age-dependent penetrance. In IPF patients with telomerase mutations, the mean age of onset is 51 years, although IPF can manifest as late as the ninth decade of life $\mathrm{e}^{70,71}$. IPF is therefore one of the latest adult-onset presentations of a Mendelian disorder. Because IPF affects an estimated 100,000 individuals in the United 
States alone, lung disease is the most prevalent manifestation of mutant telomere genes ${ }^{12}$. In addition, 3-5\% of aplastic anaemia patients carry mutant TERT and TR genes ${ }^{41,72,73}$. Liver cirrhosis, which is a known complication of dyskeratosis congenita, can also be a first adult-onset presentation of mutant telomerase genes ${ }^{39,74}$. The spectrum of monogenic telomere-mediated disorders is therefore broad, and the historically coined classic dyskeratosis congenita criteria identify only a small subset (perhaps less than 5\%) of affected individuals ${ }^{12}$.

\section{The telomere syndrome concept}

The phenotypic heterogeneity caused by mutant telomere genes (summarized in Table 1) may initially give the impression that telomere shortening causes isolated cases of IPF, aplastic anaemia or dyskeratosis congenita. However, affected individuals often have subclinical disease concurrently in other organs, even when symptoms related to a single disorder predominate ${ }^{13,39}$. For example, patients with IPF who have mutant telomerase genes are at an increased risk of developing bone marrow failure and liver disease ${ }^{54,71}$. Conversely, individuals with telomere-related aplastic anaemia have an increased incidence of fatal pulmonary fibrosis when they are exposed to pulmonary toxic drugs in the bone marrow transplant setting, even though they may have previously had no symptoms ${ }^{58,71}$. Indeed, the co-occurrence of IPF and bone marrow failure, along with liver cirrhosis, is specific to and highly predictive of a germline telomere maintenance defect ${ }^{13,39,71}$. The shared underlying telomere defect in aplastic anaemia and IPF brings together clinical entities that were previously considered to be disparate and defines a recognizable syndrome complex that predominantly manifests in adults, in contrast to dyskeratosis congenita. Recognizing the adult manifestations of the telomere syndrome spectrum is important for diagnostic and treatment decisions in several common, important clinical settings ${ }^{12,56}$.

\section{Telomere syndromes predispose to cancer}

Patients with telomere syndromes are cancer-prone. In classic dyskeratosis congenita, where it has been studied, cancer diagnoses have been estimated to occur at an 11-fold increased incidence relative to the population in one series ${ }^{75}$. However, the cancer-related mortality is limited to approximately $10 \%$ of dyskeratosis congenita cases, with the remaining mortality attributable to the degenerative disease phenotypes described above. The cancer spectrum in dyskeratosis congenita has a predilection for high-turnover tissues with an increased incidence of squamous cell carcinomas of the skin, upper aerodigestive and anogenital tracts $^{75}$. In addition, both dyskeratosis congenita and IPF patients are prone to developing haematological malignancies, commonly manifesting as myelodysplasia or acute myeloid leukaemia ${ }^{70,75,76}$. Acute myeloid leukaemia is a known complication of aplastic anaemia, but it may possibly be a first presentation of a germline mutation in TERT or TR in a subset of familial leukaemia cases $(20 \%)^{77}$ and, at a much lower frequency, sporadic cases ${ }^{78}$.

The biological basis underlying the increased cancer incidence in dyskeratosis congenita may involve more than one mechanism. Defects in telomere function that lead to the genomic instability that is seen in some animal models have been implicated as one possible pathway ${ }^{79}$, although in most mouse studies, short telomeres have been found to be cancerprotective rather than cancer-promoting ${ }^{80}$. Telomere length limits the long-term proliferative capacity of the adaptive immune system in patients with telomere syndromes ${ }^{81}$, and this immunodeficiency in turn may lead to a failure of cancer surveillance. It is also possible that the increased cancer incidence may be intrinsic to the organ failure state itself, rather than to the telomere defect per se ${ }^{82}$. This latter model could explain the inherent increased risk of malignant transformation in both acquired and inherited forms of aplastic anaemia. 


\section{Genotype-phenotype correlations}

\section{Telomere length is a modifier of disease severity}

Mutations in TERT and TR are the most commonly identifiable defects in monogenic telomere syndromes. They manifest in an autosomal-dominant inheritance pattern because complete or partial loss-of-function of one allele is sufficient to perturb telomere maintenance ${ }^{38,39,41}$. The dominant pattern of inheritance in affected families distinguishes these essential telomerase genes, with their strict gene dosage requirement, as a rare exception among the usually recessive DNA repair disorders. They are therefore also substantially more prevalent. The most compelling evidence for the causal role of telomere shortening as a primary modifier of disease is that families with mutant telomerase genes display genetic anticipation ${ }^{39,83}$. In an autosomal-dominant family with a single mutant telomerase gene, adults with long telomeres may not develop disease until the seventh decade, their immediate offspring may show disease in mid-life, and in turn their progeny may be severely affected in childhood ${ }^{39}$. This anticipation closely parallels the progressive telomere shortening with each successive generation and occurs because telomeres shorten in germ cells, and the shortened telomeres are transmitted to progeny along with the mutant telomerase gene (Fig. 3a). Genetic anticipation due to telomere shortening was initially described in telomerase-null mice that similarly display progressively worsening phenotypes in late generations ${ }^{84,85}$. Aside from trinucleotide repeat expansion, telomere shortening is the only other characterized molecular mechanism of genetic anticipation in autosomal-dominant disorders.

\section{Telomere length is a modifier of disease type}

In autosomal-dominant families, the phenotype also predictably evolves with progressive telomere shortening. In earlier generations, pulmonary fibrosis is usually the primary manifestation, whereas in later generations, bone marrow failure in younger individuals is seen as a first complication ${ }^{71}$. On the basis of this evolving pattern, dyskeratosis congenita - with its classic mucocutaneous features - is predicted to manifest eventually in subsequent generations ${ }^{71}$ (Fig. 3b). Thus the entire spectrum of telomere-mediated disease can be seen within a single family, although the number of generations across which the disease evolves from a lung-predominant to a bone-marrow-predominant phenotype depends in part on the degree of telomerase loss-of-function and probably on the initial telomere length in the founder ${ }^{39,76}$. This unfolding pattern of disease in autosomal-dominant telomere syndromes is unique among Mendelian disorders. It can pose clinical challenges towards recognizing the genetic basis because in families, older generations may not develop disease until long after a young family member is diagnosed, and the disease type may be different. This heterogeneity also makes for complex clinical genetic counselling discussions. The extent of telomere shortening also correlates with the disease type and severity beyond autosomal-dominant families ${ }^{13,56,62,86}$ (Fig. 2). Hence, the degree of telomere shortness is a determinant of both disease severity and type.

\section{Telomere length is a heritable trait}

\section{Evidence from mouse studies}

Even when the telomere maintenance genes are intact, there is compelling evidence from model systems that telomere length - 'the telotype' - is a uniquely inherited genotype ${ }^{36,82,87}$. In most Mus musculus laboratory strains, the mean telomere length is $\sim 50$ $\mathrm{kb}$. This contrasts with Mus castaneus mice, a wild-derived strain with a shorter mean telomere length $(\sim 15 \mathrm{~kb})$ and a homogeneous telomere length distribution comparable to humans. $M$. castaneus therefore offers an opportunity to model telomere dynamics relevant to humans in a defined genetic background $36,40,88$. When quantified, telomere length is short 
in wild-type offspring of parent $M$. castaneus mice that have short telomeres, indicating that telomere length is inherited ${ }^{36,82}$ (Fig. 3c). Because these offspring mice are wild-type at every gene locus but have short telomeres, they are referred to as ' $w t$ "' in the literature ${ }^{36,82}$. $\mathrm{wt}^{*}$ mice provide a model for testing whether short telomeres on their own are sufficient to cause disease. Indeed, $\mathrm{wt}^{*}$ mice show the same degenerative phenotypes as telomerase-null mice, albeit in a milder form ${ }^{36,82}$. Importantly, the telomere-related phenotypes can persist in $\mathrm{wt}^{*}$ mice for several generations, until the telomere length set point is restored ${ }^{82}$ (Fig. 3c). The influence of parental telomere length in progeny occurs because telomere elongation, even at wild-type levels of telomerase, is only incremental during development, and telomerase restores the length of some, but not all, short telomeres ${ }^{82}$. Therefore, telomere length is inherited as a unique genotype, and its inheritance can be uncoupled from the telomerase and telomere gene loci.

\section{Heritability of telomere length in humans}

The heritability of telomere length is also supported by human studies. Progeny of individuals with TERT or TR mutations are known to have short telomeres relative to agematched controls even when they do not inherit a mutant gene ${ }^{70,76,89}$ (Fig. 3c). It still remains unclear, however, whether the telomere shortening in these individuals is a risk factor for telomere-mediated phenotypes. In addition to studies in families, a number of population-based twin and non-twin studies have shown that parental telomere length (especially the paternal) influences offspring telomere length with heritability estimates ranging from 0.36-0.84 (reviewed in Ref. 90). These observations collectively support that telomere length is a genetically determined trait and that short telomeres are probably sufficient to cause disease phenotypes within similar thresholds to those seen in monogenic disorders. Because telomere length is polymorphic in populations and a shorter length accumulates with age, it is intriguing to consider that the short telotype may contribute to the missing heritability for disorders that are considered to have complex inheritance, especially those that have an age-dependent penetrance.

\section{Mechanisms of telomere-mediated disease}

Dissecting the underlying molecular mechanisms of telomere-mediated disease has important clinical implications because currently available treatments are limited and do not reverse the underlying pathology except with organ transplantation ${ }^{13}$. On a molecular level, telomere dysfunction is thought to be a consequence of shortening the telomeric DNA repeat tracts to the extent that they no longer support a functional shelterin complex ${ }^{18}$. The short, dysfunctional telomeres trigger a DNA damage response that resembles the response elicited by DNA double-strand breaks ${ }^{91-94}$. The consequent signalling cascades activate checkpoints that induce either cellular senescence or apoptosis, and in at least some contexts both processes occur simultaneously $82,85,91,95$. The downstream effector pathways of telomereinduced senescence are largely p53-dependent ${ }^{96}$, but there may be involvement of the retinoblastoma protein (RB) pathway in some settings ${ }^{97}$. The effector pathway involved may be cell- or tissue-type-specific, similarly to the responses to non-telomeric DNA damage ${ }^{98}$.

Although short telomeres cause similar cellular responses (namely, apoptosis and senescence) in different tissues, telomere-mediated disease manifests as apparently diverse disease processes. This is evident in the contrast between the bone marrow failure state of aplastic anaemia and the scar-forming phenotype of IPF. The telomerase-knockout mouse has provided an important model for understanding telomere-mediated disease mechanisms because there is a remarkable convergence with human disease phenotypes (an overview is shown in Table 2) $36,82,84,85,97,99-111$. Although it was initially clear that high-turnover tissues are particularly sensitive to telomere length ${ }^{85,101,112}$, more recently it has been recognized that telomere dysfunction causes prominent phenotypes in slow-turnover 
tissues $97,99,100,103$ (Table 2). Clinically, this is most apparent in the high penetrance of pulmonary disease in telomerase mutation carriers, even though the lung has a slow mitotic rate ${ }^{56,99}$. We propose that at least three primary mechanisms explain the diverse telomeremediated disease phenotypes. These are discussed separately below within the organ context in which they have been considered, although almost certainly overlapping mechanisms have a role.

\section{Stem cell failure in highly proliferative tissues}

Cell turnover is remarkably high in the haematopoietic compartment, where an estimated $10^{9}$ cells are produced every hour ${ }^{113}$. It is therefore not surprising that telomere-associated disease manifests so prominently in the bone marrow. Haematopoiesis relies on the selfrenewal and differentiation capacity of a well-characterized oligoclonal stem cell compartment. In both humans and mice, there is clear evidence that short telomeres cause quantitative and qualitative defects in HSCs, which manifest as stem cell exhaustion $^{36,41,71,114-117}$ (Fig. 4). The cellular mechanisms and the downstream effectors of telomere-mediated stem cell failure are not completely known, but deletion of cyclindependent kinase inhibitor 1a (Cdkn1a), which encodes p21, a transcriptional target of p53, partially rescues the HSC self-renewal defect in mice ${ }^{118}$. In humans, the aplastic anaemia phenotype can be reversed with allogeneic stem cell transplant, indicating that this telomere-related stem cell failure state is primarily cell-autonomous. Telomere dysfunction also causes stem cell failure phenotypes in other tissues. For example, in the intestinal epithelium, it manifests as villous atrophy due to a loss of crypt stem cells $\mathrm{s}^{36,101,118}$.

\section{Multiple hits are additive to telomere dysfunction in slow-turnover tissues}

In contrast to the bone marrow, in the lung, cell turnover is very slow ( $2 \%$ per week in murine alveolar epithelial cells) ${ }^{99}$. Moreover, the telomere defect alone is not sufficient to induce spontaneous lung disease in mice ${ }^{99}$. Instead, a second insult is required, and when mice with short telomeres are experimentally exposed to cigarette smoke, which is known to accelerate disease onset in human telomerase mutation carriers, they develop lung disease ${ }^{99}$. In this setting, the cigarette smoke causes additive damage to dysfunctional telomeres in lung epithelial cells. The cumulative effect is likely to reach a threshold of cellular damage that develops into an airspace destruction phenotype recognized as emphysema. The requirement for a 'second hit' in the lung may be related to the fact that its basal proliferation rate is very slow, and therefore replicative exhaustion is delayed. Indeed, in mouse models, short telomeres have been shown to lower the disease threshold to other exogenous and endogeneous damage, such as $\gamma$-irradiation ${ }^{119}$ and endoplasmic reticulum stress due to protein misfolding ${ }^{97}$ (Fig. 5a). A model that requires multiple additional hits for phenotypes to manifest in slow-turnover tissues could explain why telomere-mediated lung disease represents an attenuated, adult-onset phenotype that is commonly seen after middle age ${ }^{12,99}$.

How telomere dysfunction causes tissue remodelling, as seen in fibrosis (in the lung and liver), as well as air space destruction in emphysema is not fully understood. Because telomere dysfunction causes epithelial defects in other tissues, it has been hypothesized that the fibrotic phenotypes may be consequences of epithelial stem cell exhaustion ${ }^{56}$. One model to explain the progressive fibrosis that characterizes these disorders is that epithelial senescence or apoptosis stimulates a lung-remodelling response ${ }^{56,99}$. Indeed, some types of cellular senescence, including the telomere-induced replicative type, are associated with an in vitro senescence-associated secretory phenotype (SASP), where cytokines and proteases are detected in culture media ${ }^{120}$. Differential secretory profiles have also been detected in sera from mice with short telomeres ${ }^{121}$. Therefore, telomere dysfunction in 
epithelial cells, or perhaps another cell type, might cause parenchymal organ remodelling, which manifests as fibrosis and/or emphysema $46,54,99$.

\section{Exocytosis defects in pancreatic $\beta$-cells}

Although telomere dysfunction causes obvious histopathology in the bone marrow and parenchymal organs, there is evidence that in some settings, short dysfunctional telomeres compromise organ homeostasis even when cell mass is preserved. This mechanism has been elucidated in adult mouse $\beta$-cells of the pancreatic islets, which have a fairly slow turnover (4\% per week). Short telomeres cause spontaneous insulin secretion defects in vivo and in vitro, even when the $\beta$-cell mass is intact ${ }^{97}$ (Fig. 5b). Although they appear morphologically normal, mouse $\beta$-cells with dysfunctional telomeres show the hallmarks of senescence. They have an activated DNA damage response, impaired proliferation, $\mathrm{p} 16^{\mathrm{INK} 4 \mathrm{~A}}$ upregulation and altered gene expression ${ }^{97}$. The dysregulation of gene expression affects pathways that are essential for insulin secretion signalling and exocytosis, including mitochondrial function and $\mathrm{Ca}^{2+}$ handling ${ }^{97}$. Therefore, it seems that telomere-induced senescence represents more than a loss of replicative potential and can limit cellular function even when cells appear morphologically intact ${ }^{97}$. Gene expression changes due to telomere shortening also occur in vitro in fibroblasts undergoing replicative senescence ${ }^{122}$. Notably, impairment of insulin secretion in the presence of an intact $\beta$-cell mass also occurs in the early stages of human age-related diabetes ${ }^{123}$. The fact that the gene expression changes that occur during telomere-induced senescence cause functional changes in the absence of structural tissue disruption highlights a novel mechanism by which senescence and its associated gene expression changes cause disease. Shortened dysfunctional telomeres in other mouse cell types, such as cardiac myocytes and hepatocytes, have also been associated with decreased mitochondrial copy number and defective oxidative metabolism ${ }^{103}$. In these tissues, the metabolic dysfunction appears to be due to the effect of downregulation of PGC1a, which is a transcriptional co-activator that is important for mitochondrial biogenesis ${ }^{103}$. Future studies may unravel a role of telomere dysfunction in other secretory tissues, such as the nervous system, which like the endocrine pancreas manifests an age-dependent functional decline.

\section{Summary and implications}

Telomere syndromes represent an archetype of premature-ageing syndromes because the short telomere defect they share is progressively acquired with age in humans. Their recognition as a syndrome spectrum has important clinical implications because it brings together seemingly unrelated disease states that share the shortened telomere pathology, as well as overlapping phenotypes. There is compelling evidence that telomere length is heritable, and because it is a measurable genotype it may eventually be shown to account for previously missing heritability of a subset of age-dependent complex disorders. Beyond its canonical phenotypes in high-turnover tissues, telomere dysfunction is sufficient to cause and indeed commonly causes - degenerative phenotypes in slow-turnover tissues. These additional phenotypes now extend the scope of telomere-mediated disease into clinical contexts of prevalent conditions, such as IPF and diabetes.

The now-evident connections between telomere biology and disease are expected to evolve in the coming years. As the tools for understanding the basis of Mendelian disorders continue to abound, novel genes in uncharacterized telomere syndrome cases almost certainly will emerge. Such discoveries would enrich the understanding of how telomeres are maintained. With the increasing clinical appreciation of new disease patterns and the availability of genetic testing, defining how telomere biology can inform individualized medicine decisions will be important. Another important challenge that emerges from the 
clinical connections we have discussed here will be how to integrate the science of telomeres into advancing the understanding of a number of untreatable conditions.

Relevantly to the topic of this Review, we emphasize that telomere biology research started with a curiosity-driven focus on the molecular mechanisms of chromosome biology. Connections to disease followed decades after the fundamental foundations were laid, in contrast to much human genetics-initiated investigation. Many of the early discoveries came from studying simple organisms, such as the protozoan Tetrahymena thermophila and yeasts, in which clinical implications could not have been prospectively envisioned ${ }^{6}$. The emerging appreciation for the scope of telomere-mediated disease now in turn poses new possibilities to unravel still-puzzling fundamental aspects of telomeres that can inform clinical paradigms.

\section{Acknowledgments}

Much of the basic biology that is relevant to disease and that is discussed in this Review has been studied in a number of model organisms, and we acknowledge that owing to space limitations we could not reference that important work comprehensively. We are grateful to several colleagues and laboratory members for helpful discussions and comments on the manuscript. M.A. acknowledges research support from the US National Institutes of Health Heart, Lung and Blood Institute (NHLBI), the US National Cancer Institute (NCI) and the Maryland Stem Cell and Flight Attendants Medical Research Foundations. E.H.B. acknowledges support from the US National Institute of General Medical Sciences (NIGMS) and the NCI.

\section{Glossary}

Senescence

Pulmonary fibrosis

Cajal body

Haploinsufficiency

Oral leukoplakia

Nail dystrophy

Exudative retinopathy

Coats plus syndrome

Aplastic anaemia

Genetic anticipation
Classically defined as a permanent arrest in the cell cycle in G0.

A scarring disorder of the lung in which alveolar structures are replaced with extracellular matrix components such as collagen.

A small subnuclear organelle that contains the telomerase ribonucleoprotein complex, as well as other newly assembled ribonucleoproteins.

A state in a diploid organism whereby one normal gene copy is insufficient for normal function.

White patches in the mucosa of the mouth; this is often considered to be a precancerous state.

Abnormal or absent finger nails.

A condition in which white-yellow spots are seen in the retina, indicating damage to retina blood vessels. When it is an isolated finding, it is often referred to as Coats disease.

A syndrome defined by multiple congenital anomalies that are beyond the retinal abnormalities of Coats disease patients.

A bone marrow failure state characterized by low blood counts and a paucity of haematopoietic cells in the bone marrow.

A pattern by which a certain phenotype manifests at an earlier age and with increasing severity with successive generations in autosomal-dominant disorders. 
Heritability

Missing heritability

Allogeneic stem cell transplant

Cell-autonomous

Crypt stem cells

Tissue remodeling

Senescence-associated secretory phenotype (SASP)
A quantification of the genetic component contributing to a specific trait.

The state in which the specific genotypes underlying the inheritance of a certain trait are not known.

Transplant of stem cells, most frequently bone-marrowderived, from an alternative donor to replace a failed organ.

An effect that is intrinsic to a specific cell type and not to an independent factor beyond that cell type.

Cells in the intestinal crypt that are responsible for the regenerative capacity of the epithelial protective barrier in the intestine.

The process by which tissue structures change, often in the setting of recovery from injury or healing.

The phenomenon by which cultured senescent cells secrete growth factors, cytokines and proteases.

\section{References}

1. Blackburn EH. Telomeres and telomerase: the means to the end (Nobel lecture). Angew. Chem. Int. Edn Engl. 2010; 49:7405-7421.

2. Harley CB, Futcher AB, Greider CW. Telomeres shorten during ageing of human fibroblasts. Nature. 1990; 345:458-460. [PubMed: 2342578]

3. Allsopp RC, et al. Telomere length predicts replicative capacity of human fibroblasts. Proc. Natl Acad. Sci. USA. 1992; 89:10114-10118. [PubMed: 1438199] . References 2 and 3 showed that telomere length shortens in human cells with age and limits their in vitro replicative potential.

4. Greider CW, Blackburn EH. Identification of a specific telomere terminal transferase activity in Tetrahymena extracts. Cell. 1985; 43:405-413. [PubMed: 3907856]

5. Greider CW, Blackburn EH. The telomere terminal transferase of Tetrahymena is a ribonucleoprotein enzyme with two kinds of primer specificity. Cell. 1987; 51:887-898. [PubMed: 3319189]

6. Blackburn EH, Greider CW, Szostak JW. Telomeres and telomerase: the path from maize, Tetrahymena and yeast to human cancer and aging. Nature Med. 2006; 12:1133-1138. [PubMed: 17024208]

7. Kim NW, et al. Specific association of human telomerase activity with immortal cells and cancer. Science. 1994; 266:2011-2015. [PubMed: 7605428] . In this study, telomerase activity was found to be enriched in cancer and germ cells, suggesting that telomerase has a role in extending replicative potential.

8. Buseman CM, Wright WE, Shay JW. Is telomerase a viable target in cancer? Mutat. Res. 2012; 730:90-97. [PubMed: 21802433]

9. Heiss NS, et al. X-linked dyskeratosis congenita is caused by mutations in a highly conserved gene with putative nucleolar functions. Nature Genet. 1998; 19:32-38. [PubMed: 9590285]. This study identified mutations in the $\mathrm{X}$-linked $\mathrm{DKCl}$ gene as a first cause of dyskeratosis congenita.

10. Mitchell JR, Cheng J, Collins K. A box H/ACA small nucleolar RNA-like domain at the human telomerase RNA 3' end. Mol. Cell. Biol. 1999; 19:567-576. [PubMed: 9858580]

11. Mitchell JR, Wood E, Collins K. A telomerase component is defective in the human disease dyskeratosis congenita. Nature. 1999; 402:551-555. [PubMed: 10591218] . This study showed that dyskerin is essential for telomerase RNA stability and that dyskeratosis congenita cell lines have a short telomere length, linking this disease with defects in telomere maintenance. 
12. Armanios M. Telomerase and idiopathic pulmonary fibrosis. Mutat. Res. 2012; 730:52-58. [PubMed: 22079513]

13. Armanios M. Syndromes of telomere shortening. Annu. Rev. Genom. Hum. Genet. 2009; 10:4561.

14. Moyzis RK, et al. A highly conserved repetitive DNA sequence, (TTAGGG)n, present at the telomeres of human chromosomes. Proc. Natl Acad. Sci. USA. 1988; 85:6622-6626. [PubMed: 3413114]

15. Allshire RC, et al. Telomeric repeat from T. thermophila cross hybridizes with human telomeres. Nature. 1988; 332:656-659. [PubMed: 2833706]

16. Vaziri H, et al. Loss of telomeric DNA during aging of normal and trisomy 21 human lymphocytes. Am. J. Hum. Genet. 1993; 52:661-667. [PubMed: 8460632]

17. de Lange T. Shelterin: the protein complex that shapes and safeguards human telomeres. Genes Dev. 2005; 19:2100-2110. [PubMed: 16166375]

18. Palm W, de Lange T. How shelterin protects mammalian telomeres. Annu. Rev. Genet. 2008; 42:301-334. [PubMed: 18680434]

19. Surovtseva YV, et al. Conserved telomere maintenance component 1 interacts with STN1 and maintains chromosome ends in higher eukaryotes. Mol. Cell. 2009; 36:207-218. [PubMed: 19854131]

20. Miyake Y, et al. RPA-like mammalian Ctc1-Stn1-Ten1 complex binds to single-stranded DNA and protects telomeres independently of the Pot1 pathway. Mol. Cell. 2009; 36:193-206. [PubMed: 19854130]

21. Price CM, et al. Evolution of CST function in telomere maintenance. Cell Cycle. 2010; 9:31573165. [PubMed: 20697207]

22. Gu P, et al. $C T C 1$ deletion results in defective telomere replication, leading to catastrophic telomere loss and stem cell exhaustion. EMBO J. 2012; 31:2309-2321. [PubMed: 22531781]

23. Greider CW, Blackburn EH. A telomeric sequence in the RNA of Tetrahymena telomerase required for telomere repeat synthesis. Nature. 1989; 337:331-337. [PubMed: 2463488]

24. Lingner J, et al. Reverse transcriptase motifs in the catalytic subunit of telomerase. Science. 1997; 276:561-567. [PubMed: 9110970]

25. Feng J, et al. The RNA component of human telomerase. Science. 1995; 269:1236-1241. [PubMed: 7544491]

26. Podlevsky JD, Chen JJ. It all comes together at the ends: telomerase structure, function, and biogenesis. Mutat. Res. 2012; 730:3-11. [PubMed: 22093366]

27. Blackburn EH, Collins K. Telomerase: an RNP enzyme synthesizes DNA. Cold Spring Harb. Perspect. Biol. 2011; 3:a003558. [PubMed: 20660025]

28. Meier UT. The many facets of H/ACA ribonucleoproteins. Chromosoma. 2005; 114:1-14. [PubMed: 15770508]

29. Chen JL, Blasco MA, Greider CW. Secondary structure of vertebrate telomerase RNA. Cell. 2000; 100:503-514. [PubMed: 10721988]

30. Venteicher AS, et al. A human telomerase holoenzyme protein required for Cajal body localization and telomere synthesis. Science. 2009; 323:644-648. [PubMed: 19179534]

31. Tycowski KT, Shu MD, Kukoyi A, Steitz JA. A conserved WD40 protein binds the Cajal body localization signal of scaRNP particles. Mol. Cell. 2009; 34:47-57. [PubMed: 19285445]

32. Diede SJ, Gottschling DE. Telomerase-mediated telomere addition in vivo requires DNA primase and DNA polymerases $\alpha$ and $\delta$. Cell. 1999; 99:723-733. [PubMed: 10619426]

33. Marcand S, Brevet V, Mann C, Gilson E. Cell cycle restriction of telomere elongation. Curr. Biol. 2000; 10:487-490. [PubMed: 10801419]

34. Teixeira MT, Arneric M, Sperisen P, Lingner J. Telomere length homeostasis is achieved via a switch between telomerase- extendible and -nonextendible states. Cell. 2004; 117:323-335. [PubMed: 15109493]

35. Erdmann N, Liu Y, Harrington L. Distinct dosage requirements for the maintenance of long and short telomeres in mTert heterozygous mice. Proc. Natl Acad. Sci. USA. 2004; 101:6080-6085. [PubMed: 15079066] 
36. Hao LY, et al. Short telomeres, even in the presence of telomerase, limit tissue renewal capacity. Cell. 2005; 123:1121-1131. [PubMed: 16360040] . In reference 36, using CAST/EiJ mice that have telomere length similar to humans, this paper established that telomerase haploinsufficiency is sufficient to cause dyskeratosis-congenita-like phenotypes. It also showed that telomere length is inherited and can cause degenerative phenotypes even when telomerase is wild-type.

37. Mozdy AD, Cech TR. Low abundance of telomerase in yeast: implications for telomerase haploinsufficiency. RNA. 2006; 12:1721-1737. [PubMed: 16894218]

38. Vulliamy T, et al. The RNA component of telomerase is mutated in autosomal dominant dyskeratosis congenita. Nature. 2001; 413:432-435. [PubMed: 11574891]

39. Armanios M, et al. Haploinsufficiency of telomerase reverse transcriptase leads to anticipation in autosomal dominant dyskeratosis congenita. Proc. Natl Acad. Sci. USA. 2005; 102:15960-15964. [PubMed: 16247010] . References 38 and 39 identified mutations in the essential telomerase genes, TERT and $T R$, in dyskeratosis congenita.

40. Strong MA, et al. Phenotypes in $m T E R T^{+/-}$and $m T E R T^{+/-}$mice are due to short telomeres, not telomere-independent functions of telomerase reverse transcriptase. Mol. Cell. Biol. 2011; 31:2369-2379. [PubMed: 21464209]

41. Yamaguchi $\mathrm{H}$, et al. Mutations in TERT, the gene for telomerase reverse transcriptase, in aplastic anemia. N. Engl. J. Med. 2005; 352:1413-1424. [PubMed: 15814878] . This study identified TERT mutations in patients with aplastic anaemia.

42. Chiu CP, et al. Differential expression of telomerase activity in hematopoietic progenitors from adult human bone marrow. Stem Cells. 1996; 14:239-248. [PubMed: 8991544]

43. Vaziri H, et al. Evidence for a mitotic clock in human hematopoietic stem cells: loss of telomeric DNA with age. Proc. Natl Acad. Sci. USA. 1994; 91:9857-9860. [PubMed: 7937905]

44. Wright WE, Piatyszek MA, Rainey WE, Byrd W, Shay JW. Telomerase activity in human germline and embryonic tissues and cells. Dev. Genet. 1996; 18:173-179. [PubMed: 8934879]

45. Greider CW. Telomerase RNA levels limit the telomere length equilibrium. Cold Spring Harb. Symp. Quant. Biol. 2006; 71:225-229. [PubMed: 17381301]

46. Zhou J, Monson EK, Teng SC, Schulz VP, Zakian VA. Pif1p helicase, a catalytic inhibitor of telomerase in yeast. Science. 2000; 289:771-774. [PubMed: 10926538]

47. Makovets S, Blackburn EH. DNA damage signalling prevents deleterious telomere addition at DNA breaks. Nature Cell Biol. 2009; 11:1383-1386. [PubMed: 19838171]

48. Hemann MT, Strong MA, Hao LY, Greider CW. The shortest telomere, not average telomere length, is critical for cell viability and chromosome stability. Cell. 2001; 107:67-77. [PubMed: 11595186] . This study established that the shortest telomeres have a genetically dominant influence on cellular phenotypes.

49. McEachern MJ, Blackburn EH. Cap-prevented recombination between terminal telomeric repeat arrays (telomere CPR) maintains telomeres in Kluyveromyces lactis lacking telomerase. Genes Dev. 1996; 10:1822-1834. [PubMed: 8698241]

50. Kaul Z, Cesare AJ, Huschtscha LI, Neumann AA, Reddel RR. Five dysfunctional telomeres predict onset of senescence in human cells. EMBO Rep. 2011; 13:52-59. [PubMed: 22157895]

51. Lin J, et al. Analyses and comparisons of telomerase activity and telomere length in human $\mathrm{T}$ and B cells: insights for epidemiology of telomere maintenance. J. Immunol. Methods. 2010; 352:7180. [PubMed: 19837074]

52. Rufer N, et al. Telomere fluorescence measurements in granulocytes and T lymphocyte subsets point to a high turnover of hematopoietic stem cells and memory T cells in early childhood. J. Exp. Med. 1999; 190:157-167. [PubMed: 10432279]

53. Aubert G, Hills M, Lansdorp PM. Telomere length measurement-Caveats and a critical assessment of the available technologies and tools. Mutat. Res. 2012; 730:59-67. [PubMed: 21663926]

54. Alder JK, et al. Short telomeres are a risk factor for idiopathic pulmonary fibrosis. Proc. Natl Acad. Sci. USA. 2008; 105:13051-13056. [PubMed: 18753630]

55. Alter BP, et al. Very short telomere length by flow fluorescence in situ hybridization identifies patients with dyskeratosis congenita. Blood. 2007; 110:1439-1447. [PubMed: 17468339]

56. Armanios MY, et al. Telomerase mutations in families with idiopathic pulmonary fibrosis. N. Engl. J. Med. 2007; 356:1317-1326. [PubMed: 17392301] . References 54-56 showed that lymphocyte 
telomere length using flow cytometry and fluorescence in situ hybridization could be a useful diagnostic marker in identifying individuals with telomere-related disease.

57. Baerlocher GM, Vulto I, de Jong G, Lansdorp PM. Flow cytometry and FISH to measure the average length of telomeres (flow FISH). Nature Protoc. 2006; 1:2365-2376. [PubMed: 17406480]

58. de la Fuente J, Dokal I. Dyskeratosis congenita: advances in the understanding of the telomerase defect and the role of stem cell transplantation. Pediatr. Transplant. 2007; 11:584-594. [PubMed: 17663679]

59. Savage SA, Alter BP. Dyskeratosis congenita. Hematol. Oncol. Clin. North Am. 2009; 23:215231. [PubMed: 19327580]

60. Vulliamy T, et al. Mutations in the telomerase component NHP2 cause the premature ageing syndrome dyskeratosis congenita. Proc. Natl Acad. Sci. USA. 2008; 105:8073-8078. [PubMed: 18523010]

61. Walne AJ, et al. Genetic heterogeneity in autosomal recessive dyskeratosis congenita with one subtype due to mutations in the telomerase-associated protein NOP10. Hum. Mol. Genet. 2007; 16:1619-1629. [PubMed: 17507419]

62. Savage SA, et al. TINF2, a component of the shelterin telomere protection complex, is mutated in dyskeratosis congenita. Am. J. Hum. Genet. 2008; 82:501-509. [PubMed: 18252230] . This paper was the first to show that mutations in a shelterin component are a cause of dyskeratosis congenita.

63. Zhong F, et al. Disruption of telomerase trafficking by TCAB1 mutation causes dyskeratosis congenita. Genes Dev. 25:11-16. [PubMed: 21205863]

64. Keller RB, et al. CTC1 mutations in a patient with dyskeratosis congenita. Pediatr. Blood Cancer. 2012; 59:311-314. [PubMed: 22532422]

65. Jyonouchi S, Forbes L, Ruchelli E, Sullivan KE. Dyskeratosis congenita: a combined immunodeficiency with broad clinical spectrum-a single-center pediatric experience. Pediatr. Allergy Immunol. 2011; 22:313-319. [PubMed: 21284747]

66. Anderson BH, et al. Mutations in CTC1, encoding conserved telomere maintenance component 1, cause Coats plus. Nature Genet. 2012; 44:338-342. [PubMed: 22267198]

67. Polvi A, et al. Mutations in CTC1, encoding the CTS telomere maintenance complex component 1, cause cerebroretinal microangiopathy with calcifications and cysts. Am. J. Hum. Genet. 2012; 90:540-549. [PubMed: 22387016] . References 66 and 67 identified CTC1 mutations in Coats plus syndrome. Reference 66 identified short telomere length in these patients, suggesting a role for telomere dysfunction in the pathophysiology of this syndrome.

68. Tsakiri KD, et al. Adult-onset pulmonary fibrosis caused by mutations in telomerase. Proc. Natl Acad. Sci. USA. 2007; 104:7552-7557. [PubMed: 17460043] . References 56 and 68 identified mutations in the essential telomerase genes in familial pulmonary fibrosis.

69. Cronkhite JT, et al. Telomere shortening in familial and sporadic pulmonary fibrosis. Am. J. Respir. Crit. Care Med. 2008; 178:729-737. [PubMed: 18635888]

70. Diaz de Leon A, et al. Telomere lengths, pulmonary fibrosis and telomerase (TERT) mutations. PLoS ONE. 2010; 5:e10680. [PubMed: 20502709]

71. Parry EM, Alder JK, Qi X, Chen JJ, Armanios M. Syndrome complex of bone marrow failure and pulmonary fibrosis predicts germline defects in telomerase. Blood. 2011; 117:5607-5611. [PubMed: 21436073]

72. Du HY, et al. TERC and TERT gene mutations in patients with bone marrow failure and the significance of telomere length measurements. Blood. 2008; 113:309-316. [PubMed: 18931339]

73. Yamaguchi $\mathrm{H}$, et al. Mutations of the human telomerase RNA gene (TERC) in aplastic anemia and myelodysplastic syndrome. Blood. 2003; 102:916-918. [PubMed: 12676774] . This study identified $T R$ mutations in patients with bone marrow failure.

74. Calado RT, et al. A spectrum of severe familial liver disorders associate with telomerase mutations. PLoS ONE. 2009; 4:e7926. [PubMed: 19936245]

75. Alter BP, Giri N, Savage SA, Rosenberg PS. Cancer in dyskeratosis congenita. Blood. 2009; 113:6549-6557. [PubMed: 19282459]

76. Alder JK, et al. Ancestral mutation in telomerase causes defects in repeat addition processivity and manifests as familial pulmonary fibrosis. PLoS Genet. 2011; 7:e1001352. [PubMed: 21483807] 
77. Kirwan M, et al. Defining the pathogenic role of telomerase mutations in myelodysplastic syndrome and acute myeloid leukemia. Hum. Mutat. 2009; 30:1567-1573. [PubMed: 19760749]

78. Calado RT, et al. Constitutional hypomorphic telomerase mutations in patients with acute myeloid leukemia. Proc. Natl Acad. Sci. USA. 2009; 106:1187-1192. [PubMed: 19147845]

79. Artandi SE, DePinho RA. Telomeres and telomerase in cancer. Carcinogenesis. 2010; 31:9-18. [PubMed: 19887512]

80. Deng Y, Chan SS, Chang S. Telomere dysfunction and tumour suppression: the senescence connection. Nature Rev. Cancer. 2008; 8:450-458. [PubMed: 18500246]

81. Knudson M, Kulkarni S, Ballas ZK, Bessler M, Goldman F. Association of immune abnormalities with telomere shortening in autosomal-dominant dyskeratosis congenita. Blood. 2005; 105:682688. [PubMed: 15238429]

82. Armanios M, et al. Short telomeres are sufficient to cause the degenerative defects associated with aging. Am. J. Hum. Genet. 2009; 85:823-832. [PubMed: 19944403]

83. Vulliamy T, et al. Disease anticipation is associated with progressive telomere shortening in families with dyskeratosis congenita due to mutations in TERC. Nature Genet. 2004; 36:447-449. [PubMed: 15098033] . References 83 and 39 (above) showed that mutations in the essential telomerase genes cause genetic anticipation in autosomal-dominant dyskeratosis congenita.

84. Blasco MA, et al. Telomere shortening and tumor formation by mouse cells lacking telomerase $R N A$. Cell. 1997; 91:25-34. [PubMed: 9335332]

85. Lee HW, et al. Essential role of mouse telomerase in highly proliferative organs. Nature. 1998; 392:569-574. [PubMed: 9560153] . References 84 and 85 are two landmark papers that established that telomerase itself is not essential and that short telomeres cause apoptosis and cell loss in high-turnover tissues.

86. Alter BP, et al. Telomere length is associated with disease severity and declines with age in dyskeratosis congenita. Haematologica. 2012; 97:353-359. [PubMed: 22058220]

87. Makovets S, Williams TL, Blackburn EH. The telotype defines the telomere state in Saccharomyces cerevisiae and is inherited as a dominant non- Mendelian characteristic in cells lacking telomerase. Genetics. 2008; 178:245-257. [PubMed: 18202371]

88. Hemann MT, Greider CW. Wild-derived inbred mouse strains have short telomeres. Nucleic Acids Res. 2000; 28:4474-4478. [PubMed: 11071935]

89. Goldman F, et al. The effect of TERC haploinsufficiency on the inheritance of telomere length. Proc. Natl Acad. Sci. USA. 2005; 102:17119-17124. [PubMed: 16284252]

90. Aviv A. Genetics of leukocyte telomere length and its role in atherosclerosis. Mutat. Res. 2012; 730:68-74. [PubMed: 21600224]

91. d'Adda di Fagagna F, et al. A DNA damage checkpoint response in telomere-initiated senescence. Nature. 2003; 426:194-198. [PubMed: 14608368]

92. Enomoto S, Glowczewski L, Berman J. MEC3, MEC1, and DDC2 are essential components of a telomere checkpoint pathway required for cell cycle arrest during senescence in Saccharomyces cerevisiae. Mol. Biol. Cell. 2002; 13:2626-2638. [PubMed: 12181334]

93. IJpma A, Greider CW. Short telomeres induce a DNA damage response in Saccharomyces cerevisiae. Mol. Biol. Cell. 2003; 14:987-1001. [PubMed: 12631718]

94. Nautiyal S, DeRisi JL, Blackburn EH. The genome-wide expression response to telomerase deletion in Saccharomyces cerevisiae. Proc. Natl Acad. Sci. USA. 2002; 99:9316-9321. [PubMed: 12084816]

95. Hemann MT, et al. Telomere dysfunction triggers developmentally regulated germ cell apoptosis. Mol. Biol. Cell. 2001; 12:2023-2030. [PubMed: 11452000]

96. Chin L, et al. p53 deficiency rescues the adverse effects of telomere loss and cooperates with telomere dysfunction to accelerate carcinogenesis. Cell. 1999; 97:527-538. [PubMed: 10338216]

97. Guo N, et al. Short telomeres compromise $\beta$-cell signaling and survival. PLoS ONE. 2011; 6:e17858. [PubMed: 21423765]

98. Campisi J. Senescent cells, tumor suppression, and organismal aging: good citizens, bad neighbors. Cell. 2005; 120:513-522. [PubMed: 15734683] 
99. Alder JK, et al. Telomere length is a determinant of emphysema susceptibility. Am. J. Respir. Crit. Care Med. 2011; 183:904-912. [PubMed: 21757622]

100. Leri A, et al. Ablation of telomerase and telomere loss leads to cardiac dilatation and heart failure associated with p53 upregulation. EMBO. J. 2003; 22:131-139. [PubMed: 12505991]

101. Rudolph KL, et al. Longevity, stress response, and cancer in aging telomerase-deficient mice. Cell. 1999; 96:701-712. [PubMed: 10089885]

102. Rudolph KL, Chang S, Millard M, Schreiber-Agus N, DePinho RA. Inhibition of experimental liver cirrhosis in mice by telomerase gene delivery. Science. 2000; 287:1253-1258. [PubMed: 10678830]

103. Sahin E, et al. Telomere dysfunction induces metabolic and mitochondrial compromise. Nature. 2011; 470:359-365. [PubMed: 21307849] . References 97 and 103 implicate short telomeres as a cause of mitochondrial dysfunction, a pathogenic mechanism that highlights a role for telomere dysfunction in slow-turnover tissues.

104. Herrera E, Martinez AC, Blasco MA. Impaired germinal center reaction in mice with short telomeres. EMBO. J. 2000; 19:472-481. [PubMed: 10654945]

105. Sacco A, et al. Short telomeres and stem cell exhaustion model Duchenne muscular dystrophy in mdx/mTR mice. Cell. 2010; 143:1059-1071. [PubMed: 21145579]

106. Pignolo RJ, et al. Defects in telomere maintenance molecules impair osteoblast differentiation and promote osteoporosis. Aging Cell. 2008; 7:23-31. [PubMed: 18028256]

107. Chang S, et al. Essential role of limiting telomeres in the pathogenesis of Werner syndrome. Nature Genet. 2004; 36:877-882. [PubMed: 15235603]

108. Minamino T, et al. A crucial role for adipose tissue p53 in the regulation of insulin resistance. Nature Med. 2009; 15:1082-1087. [PubMed: 19718037]

109. Lee BW, Yap HK, Quah TC, Chong A, Seah CC. T cell immunodeficiency in dyskeratosis congenita. Arch. Dis. Child. 1992; 67:524-526. [PubMed: 1580685]

110. Sznajer Y, et al. Further delineation of the congenital form of X-linked dyskeratosis congenita (Hoyeraal- Hreidarsson syndrome). Eur. J. Pediatr. 2003; 162:863-867. [PubMed: 14648217]

111. Vulliamy T, Marrone A, Dokal I, Mason PJ. Association between aplastic anaemia and mutations in telomerase RNA. Lancet. 2002; 359:2168-2170. [PubMed: 12090986]

112. Herrera E, et al. Disease states associated with telomerase deficiency appear earlier in mice with short telomeres. EMBO. J. 1999; 18:2950-2960. [PubMed: 10357808]

113. Metcalf, D. The Molecular Control of Blood Cells. Harvard Univ. Press; 1988. p. 1-22.

114. Allsopp RC, Morin GB, DePinho R, Harley CB, Weissman IL. Telomerase is required to slow telomere shortening and extend replicative lifespan of HSCs during serial transplantation. Blood. 2003; 102:517-520. [PubMed: 12663456]

115. Goldman FD, et al. Characterization of primitive hematopoietic cells from patients with dyskeratosis congenita. Blood. 2008; 111:4523-4531. [PubMed: 18310499]

116. Fogarty PF, et al. Late presentation of dyskeratosis congenita as apparently acquired aplastic anaemia due to mutations in telomerase $R N A$. Lancet. 2003; 362:1628-1630. [PubMed: 14630445]

117. Rossi DJ, et al. Deficiencies in DNA damage repair limit the function of haematopoietic stem cells with age. Nature. 2007; 447:725-729. [PubMed: 17554309]

118. Choudhury AR, et al. Cdkn1a deletion improves stem cell function and lifespan of mice with dysfunctional telomeres without accelerating cancer formation. Nature Genet. 2007; 39:99-105. [PubMed: 17143283]

119. Wong KK, et al. Telomere dysfunction impairs DNA repair and enhances sensitivity to ionizing radiation. Nature Genet. 2000; 26:85-88. [PubMed: 10973255]

120. Coppe JP, Desprez PY, Krtolica A, Campisi J. The senescence-associated secretory phenotype: the dark side of tumor suppression. Annu. Rev. Pathol. 2010; 5:99-118. [PubMed: 20078217]

121. Jiang $\mathrm{H}$, et al. Proteins induced by telomere dysfunction and DNA damage represent biomarkers of human aging and disease. Proc. Natl Acad. Sci. USA. 2008; 105:11299-11304. [PubMed: 18695223] 
122. Zhang H, Pan KH, Cohen SN. Senescencespecific gene expression fingerprints reveal celltypedependent physical clustering of up-regulated chromosomal loci. Proc. Natl Acad. Sci. USA. 2003; 100:3251-3256. [PubMed: 12626749]

123. Prentki M, Nolan CJ. Islet $\beta$ cell failure in type 2 diabetes. J. Clin. Invest. 2006; 116:1802-1812. [PubMed: 16823478]

124. Knight SW, et al. Unexplained aplastic anaemia, immunodeficiency, and cerebellar hypoplasia (Hoyeraal-Hreidarsson syndrome) due to mutations in the dyskeratosis congenita gene, DKC1. Br. J. Haematol. 1999; 107:335-339. [PubMed: 10583221]

125. Yaghmai R, et al. Overlap of dyskeratosis congenita with the Hoyeraal-Hreidarsson syndrome. J. Pediatr. 2000; 136:390-393. [PubMed: 10700698]

126. Walne AJ, Vulliamy T, Beswick R, Kirwan M, Dokal I. TINF2 mutations result in very short telomeres: analysis of a large cohort of patients with dyskeratosis congenita and related bone marrow failure syndromes. Blood. 2008; 112:3594-3600. [PubMed: 18669893]

127. Chiang YJ, Kim SH, Tessarollo L, Campisi J, Hodes RJ. Telomere-associated protein TIN2 is essential for early embryonic development through a telomerase-independent pathway. Mol. Cell. Biol. 2004; 24:6631-6634. [PubMed: 15254230] 

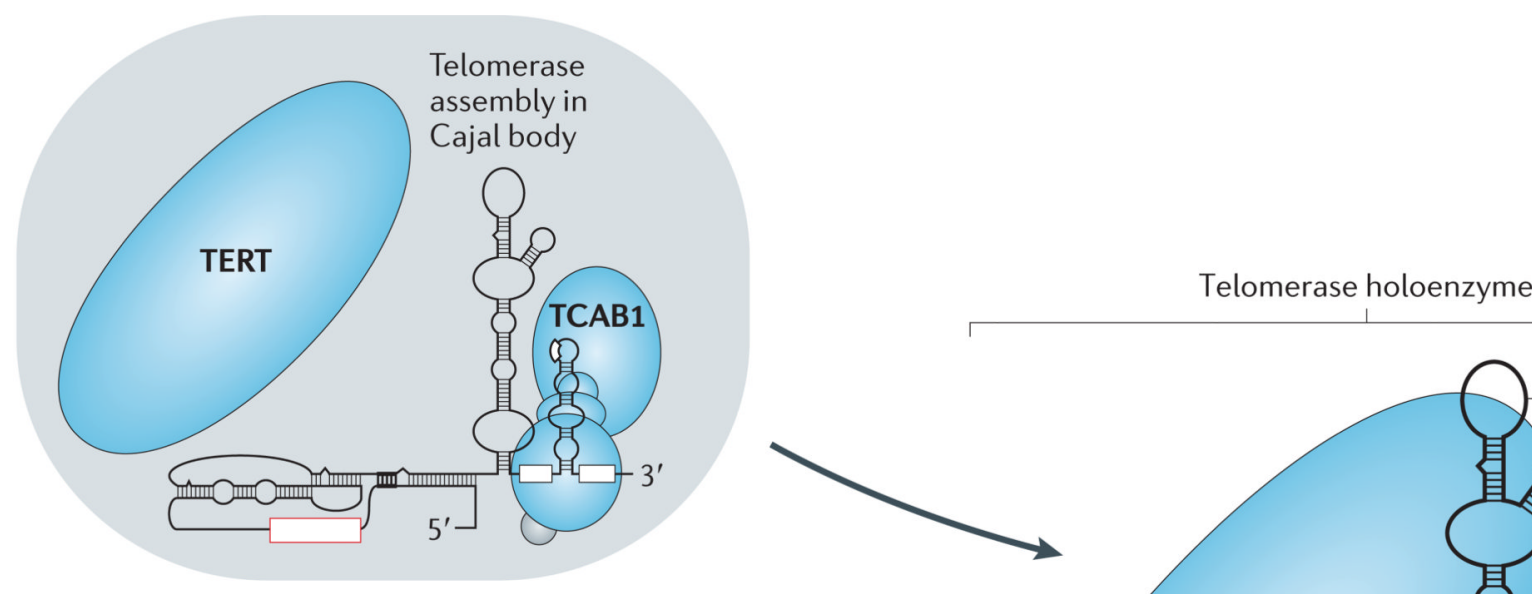

Telomerase holoenzyme

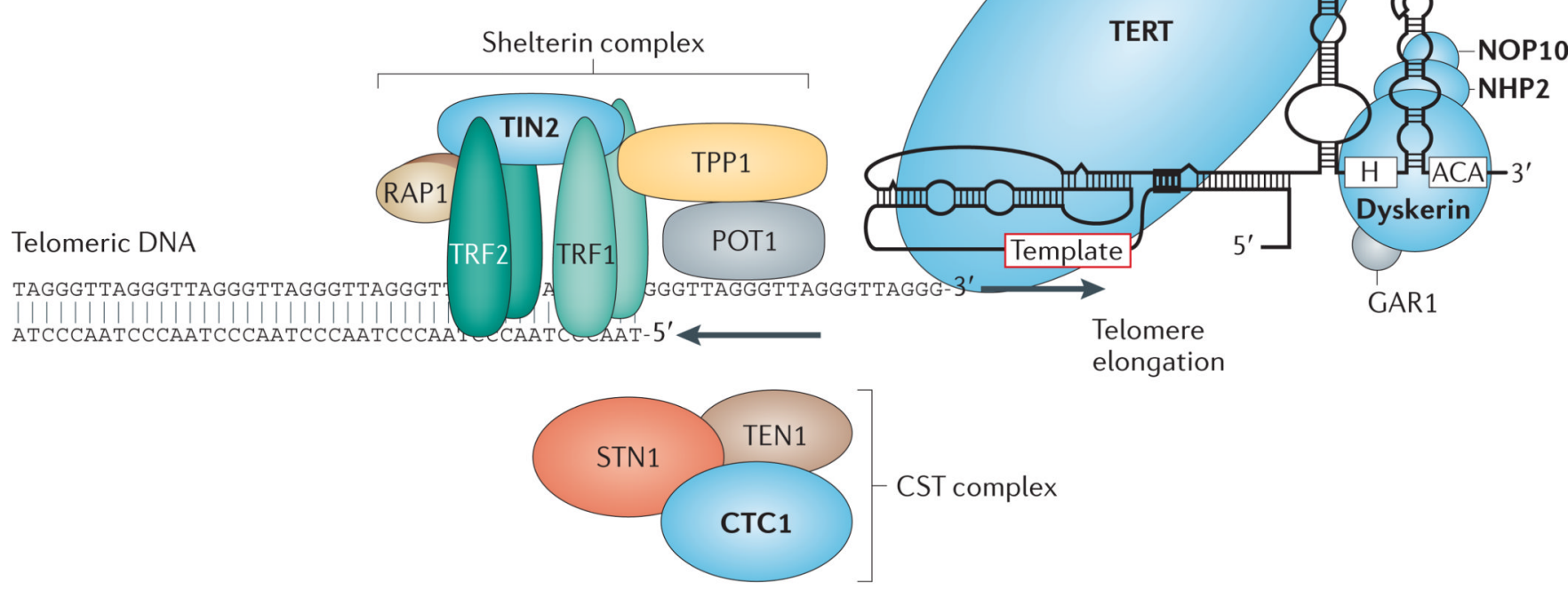

Proposed role in lagging-strand synthesis

Figure 1. Telomerase and telomere components involved in human monogenic telomere syndromes

Components for which mutations have been identified in telomere syndromes are indicated in bold type and shaded in blue. Shelterin complex components are made up of six component proteins - telomere repeat-binding factor 1 (TRF1), TRF2, repressor/activator protein 1 (RAP1), TRF1-interacting nuclear protein 2 (TIN2), TIN2-interacting protein 1 (TPP1) and protection of telomeres 1 (POT1) - which are essential for telomere protection and for regulating telomere elongation. The telomerase enzyme complex is comprised of TERT (the reverse transcriptase) and TR (the essential RNA component that contains a template for telomere repeat addition). TR contains a $3^{\prime} \mathrm{H} / \mathrm{ACA}$ box motif that binds the dyskerin protein, which is part of a larger dyskerin complex that also consists of NHP2, NOP10 and GAR1. Note that for simplicity, one dyskerin complex is shown per TR molecule, although two copies are now thought to bind each TR. Telomerase Cajal body protein 1 (TCAB1) binds a Cajal body localization motif in TR and has a role in TR trafficking and biogenesis. In the Cajal body, TR and TERT assemble into a functional holoenzyme complex. The CST complex has three components - conserved telomere protection component 1 (CTC1), suppressor of cdc thirteen 1 (STN1) and telomeric pathway with STN1 (TEN1) — which are thought to function in part in telomere lagging-strand synthesis. Figure adapted, with permission, from Ref. 13 @ (2009) Annual Reviews. 


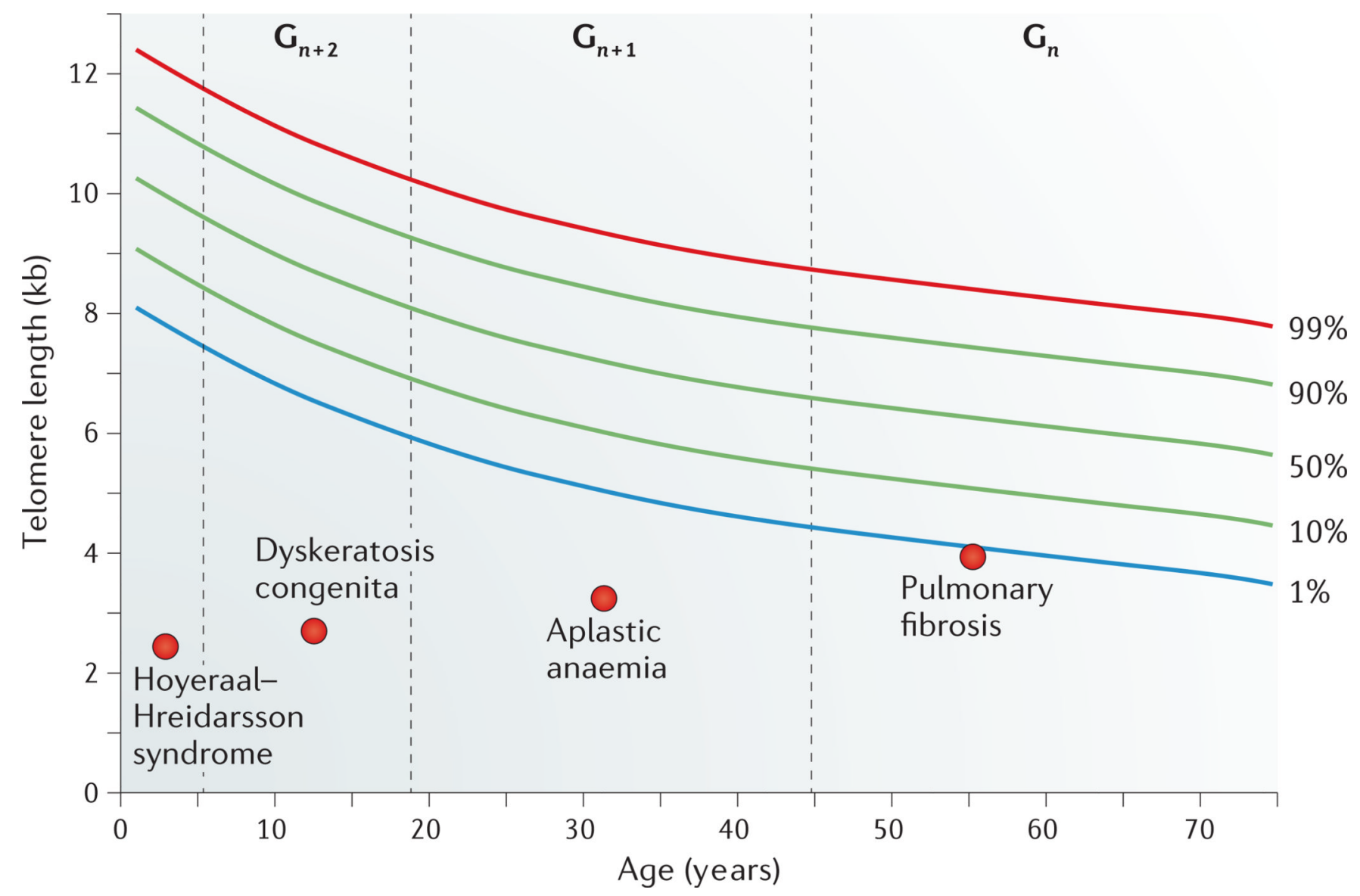

Figure 2. Age-dependent manifestations of telomere syndromes

A schematic drawing that illustrates the typical range of telomere lengths by age in, for example, peripheral blood lymphocytes. At every age, telomere length displays a normal distribution that is defined by the percentile lines labelled on the right. Telomere length in individuals with four different clinical presentations across the age range is indicated. The dashed lines represent a typical age range in which these disorders may first manifest, and ' $\mathrm{G}_{n}$ ', ' $\mathrm{G}_{n+1}$ ' and ' $\mathrm{G}_{n+2}$ ' designate three successive generations manifesting with earlieronset and evolving disease type owing to progressive telomere shortening. 

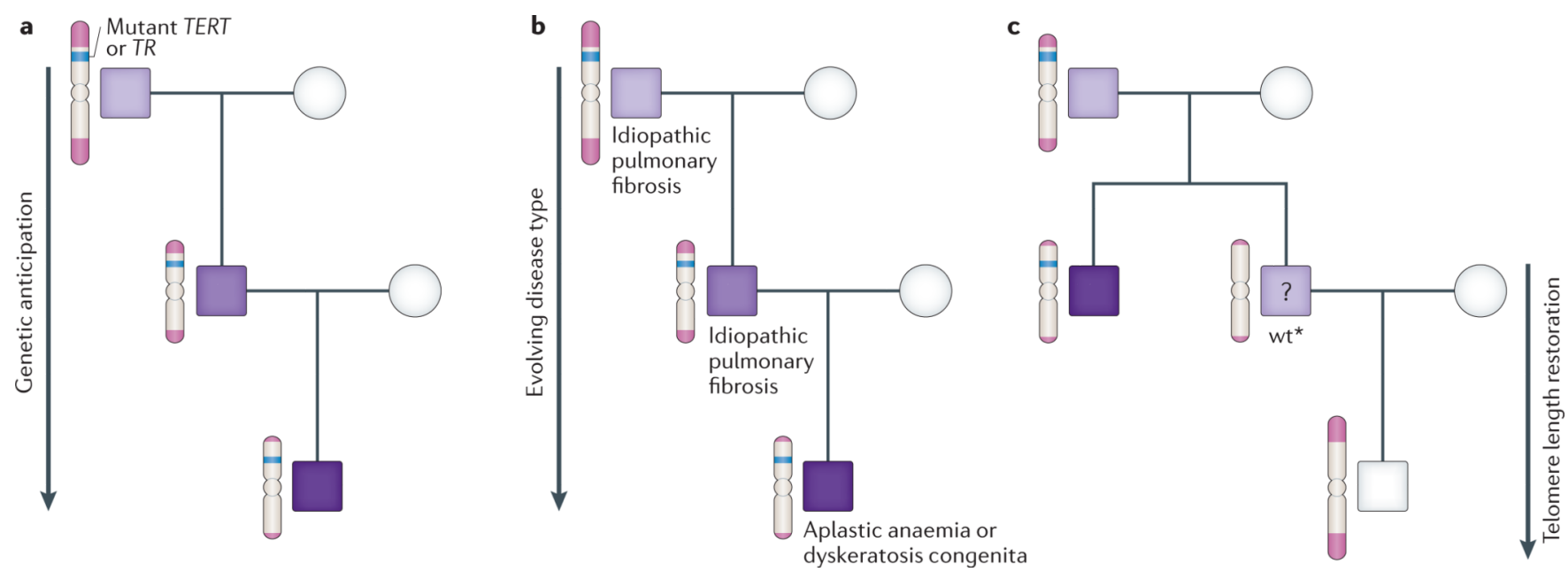

Figure 3. Unique genetics of autosomal-dominant telomere syndromes

a Schema of a typical autosomal-dominant family with an inherited mutation in TERT(the reverse transcriptase) or $T R$ (the telomerase RNA) showing earlier-onset disease with each generation, as illustrated by the darkening shades of purple. $\mathbf{b} \mid$ Disease type evolves in autosomal-dominant families from lung-predominant, which commonly manifests as idiopathic pulmonary fibrosis (IPF), to bone-marrow-failure-predominant, which presents as aplastic anaemia or dyskeratosis congenita. c| In mouse and human families, progeny of telomerase mutation carriers inherit the short telomeres even when they do not carry the mutant telomerase gene and are designated wt*. Mice with the $\mathrm{wt}^{*}$ genotype have mild telomere-mediated phenotypes, but it remains unclear whether this is the situation for human cases (as represented by the question mark). The telomere length in human families is restored in progeny of these individuals. Figure adapted, with permission, from Ref. 12 (C) (2012) Elsevier. 
a

Haematopoietic stem cells

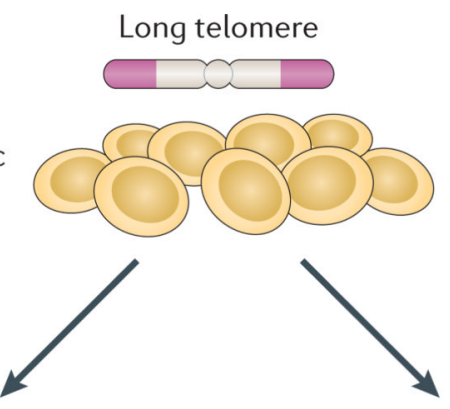

Neutrophils

Red blood cells

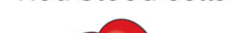

B and T lymphocytes

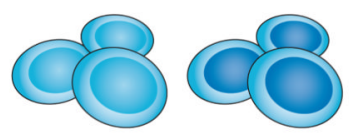

Short telomere
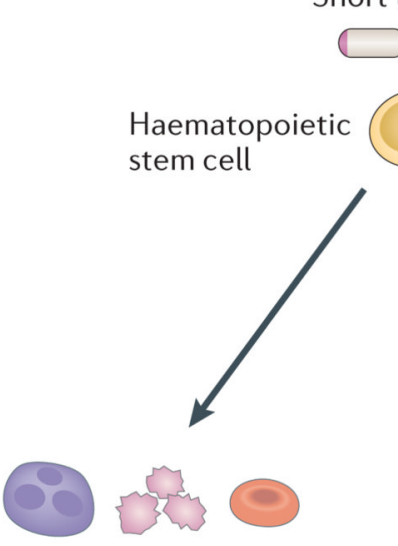

Bone marrow failure
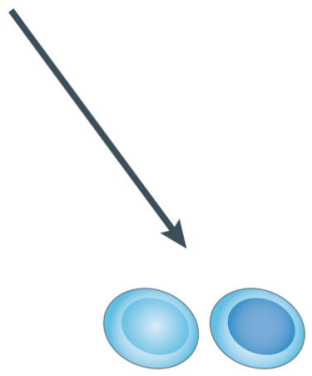

Immunosenescence

Platelets

\section{b Normal bone marrow}

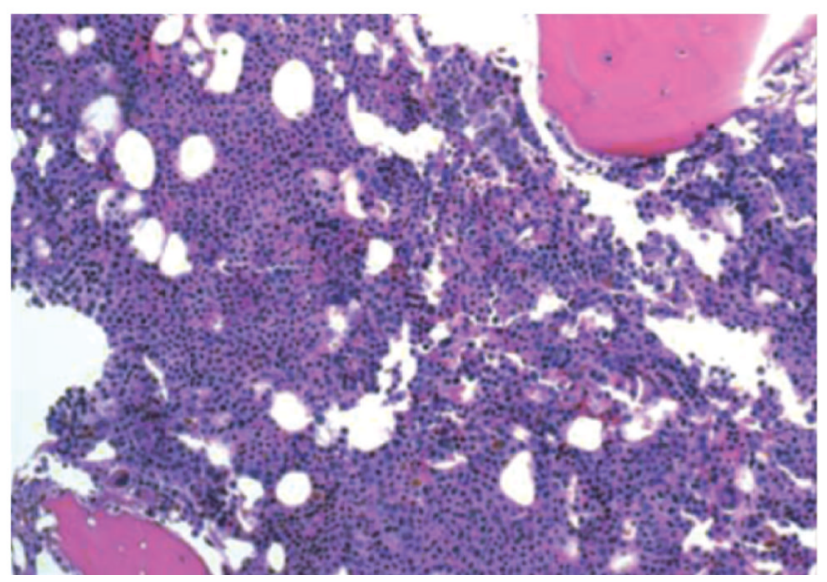

\section{Aplastic anaemia}

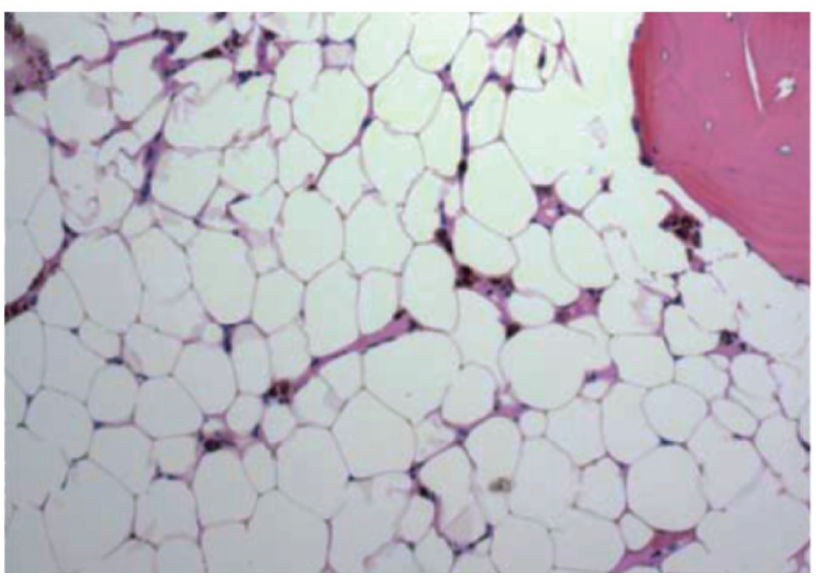

Figure 4. Short telomeres cause haematopoietic stem cell failure

a Simplified schema of the haematopoiesis hierarchy with intact telomere length (left panel) and in the presence of telomere dysfunction (right panel). Telomere dysfunction causes both quantitative and qualitative defects in haematopoietic stem cells, which cause a decrease in mature blood forms. Defects in lymphopoiesis also cause immune defects. b | Histopathology of normal bone marrow biopsy shows intact marrow cellularity and haematopoietic cellular elements (left panel). In the right panel, a photomicrograph of a bone marrow biopsy from an individual with aplastic anaemia shows acellular marrow and replacement of the marrow parenchyma by fat. Panel $\mathbf{b}$ reproduced, with permission, from Ref. 13 C (2009) Annual Reviews. 
a
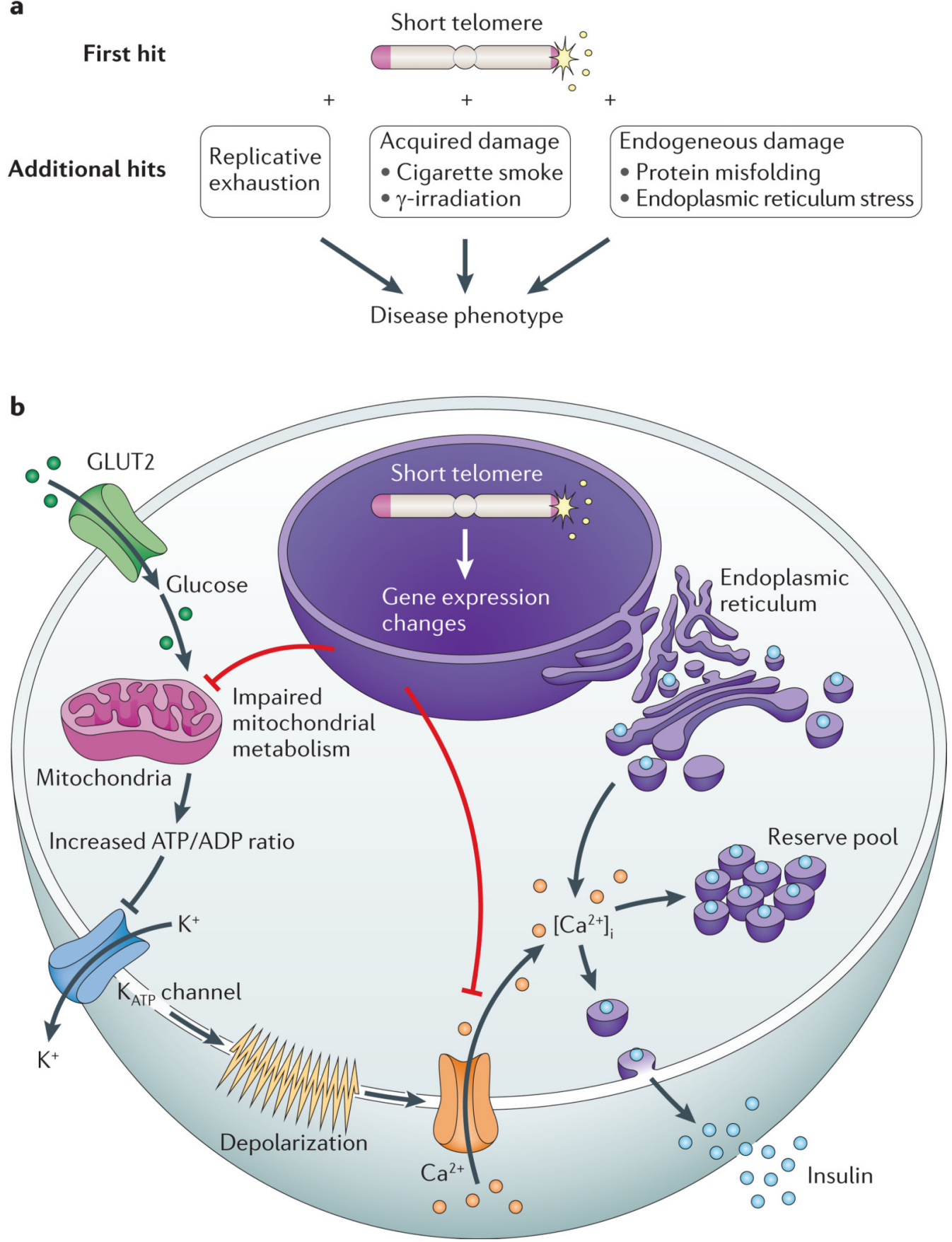

Figure 5. Mechanisms of telomere-mediated disease in slow-turnover tissues

a Telomere length lowers the threshold to endogenous and exogenous damage, which is hypothesized to precipitate disease in slow-turnover tissues. b | A schematic of an insulinproducing $\beta$-cell showing the mechanism of a telomere-mediated insulin exocytosis defect. Glucose passively enters $\beta$-cells through the glucose transporter type 2 (GLUT2; also known as SLC2A2). Following glycolysis, ATP is generated by oxidative phosphorylation in the mitochondria. The net cytosolic change of the ATP/ADP ratio leads to closure of ATPdependent $\mathrm{K}^{+}$channels and opening of $\mathrm{Ca}^{2+}$ channels. The influx of extracellular $\mathrm{Ca}^{2+}$ results in an increase in the concentration of free, intracellular $\mathrm{Ca}^{2+}\left(\left[\mathrm{Ca}^{2+}\right]_{\mathrm{i}}\right)$, which triggers 
the release of insulin from both reserve and back-up pools. Short telomeres cause gene expression changes in pancreatic islets, which are associated with global metabolic dysregulation, mitochondrial dysfunction and concurrent defects in glucose-dependent and glucose-independent $\mathrm{Ca}^{2+}$ handling. 
Table 1

Disease spectrum, frequency of gene mutations and mechanism of telomere shortening in telomere syndromes

\begin{tabular}{|c|c|c|c|c|}
\hline Gene & First diagnosis & $\begin{array}{l}\text { Mutation } \\
\text { frequency }(\%)\end{array}$ & Mechanism of telomere shortening & Refs \\
\hline \multirow{5}{*}{$\begin{array}{l}\text { TERT; } \\
T R\end{array}$} & Familial IPF & $8-15$ & \multirow{5}{*}{$\begin{array}{ll}\text { - } & \text { Partial loss-of-function } \\
\text { - } & \text { Haploinsufficiency }\end{array}$} & \multirow{5}{*}{$\begin{array}{r}36,38,39,41 \\
54,56,68,73 \\
74,77,111 \\
116\end{array}$} \\
\hline & Sporadic IPF & $1-3$ & & \\
\hline & Aplastic anaemia & $3-5$ & & \\
\hline & Autosomal dominant dyskeratosis congenita & $10^{*}$ & & \\
\hline & Familial MDS-AML & 20 & & \\
\hline \multirow[t]{3}{*}{$D K C 1$} & De novo dyskeratosis congenita & $?$ & \multirow{3}{*}{$\begin{array}{ll}\text { - } & \text { Partial loss-of-function } \\
\text { - } & \begin{array}{l}\text { Decreased TR stability and } \\
\text { biogenesis }\end{array}\end{array}$} & \multirow[t]{3}{*}{$9,11,124,125$} \\
\hline & $\mathrm{X}$-linked recessive dyskeratosis congenita & $15-25^{*}$ & & \\
\hline & Hoyeraal-Hreiderasson syndrome & $?$ & & \\
\hline \multirow[t]{4}{*}{ TINF2 } & De novo dyskeratosis congenita & $15-25^{*}$ & \multirow{4}{*}{$\begin{array}{ll}\text { - } & \text { Not completely understood } \\
\text { - } & \text { Probably dominant-negative } \\
\text { mutations }\end{array}$} & \multirow[t]{4}{*}{$62,126,127$} \\
\hline & Autosomal-dominant dyskeratosis congenita & Rare & & \\
\hline & Hoyeraal-Hreiderasson syndrome & Rare & & \\
\hline & Revesz syndrome & Rare & & \\
\hline NOP10 & Autosomal-recessive dyskeratosis congenita & $\neq$ & Presumed loss of telomerase function & 61 \\
\hline NHP2 & Autosomal-recessive dyskeratosis congenita & $\neq$ & Presumed loss of telomerase function & 60 \\
\hline$T C A B 1$ & Autosomal-recessive dyskeratosis congenita & $\neq$ & Impaired TR trafficking; loss-of-function & 63 \\
\hline \multirow[t]{2}{*}{$C T C 1$} & Coats plus syndrome & 90 & \multirow[t]{2}{*}{ Loss-of-function } & \multirow[t]{2}{*}{$22,64,66,67$} \\
\hline & Autosomal-recessive dyskeratosis congenita & $?$ & & \\
\hline
\end{tabular}

Refers to frequency of total dyskeratosis congenita patients.

tonly two cases have been reported for each of these genes in the literature to date. AML, acute myeloid leukaemia; $C T C 1$, conserved telomere protection component 1; DKC1, dyskeratosis congenita 1; IPF, idiopathic pulmonary fibrosis; MDS, myelodysplastic syndrome; TCAB1, telomerase Cajal body protein 1; TINF2, TRF1-interacting nuclear factor 2. 
Table 2

Organ-specific disease phenotypes in humans and mice with short telomeres

\begin{tabular}{|c|c|c|}
\hline Tissue type & $\begin{array}{l}\text { Disease manifestations in humans with } \\
\text { telomere syndromes }\end{array}$ & Telomere phenotypes in mice with short telomeres \\
\hline \multicolumn{3}{|l|}{ High-turnover tissues } \\
\hline Skin & Premature hair greying 58,59 & Premature hair greying ${ }^{101}$ \\
\hline Bone marrow & Aplastic anaemia $^{111,116}$ & $\begin{array}{ll}\text { - Ineffective haematopoiesis } & 36,85,101 \\
\text { - } & \text { Quantitative and qualitative HSC defects } \\
& 114,117,118\end{array}$ \\
\hline Immune & $\begin{array}{ll}\text { - } & \text { Opportunistic infections }{ }^{109} \\
\text { - } & \text { B, T and NK cell immunodeficiency } \\
\end{array}$ & $\begin{array}{ll}\text { - } & \text { Opportunistic infections }^{82} \\
\text { - } & \text { Impaired vaccine and T cell responses } \\
\text { - } & \text { Skewed T cell ratio }\left(\mathrm{CD} 4^{+} \text {to } \mathrm{CD} 8^{+}\right)^{104}\end{array}$ \\
\hline Intestinal epithelium & Enterocolitis ${ }^{65,110}$ & $\begin{array}{ll}\text { • } & \text { Enterocolitis }^{82} \\
\text { - } & \text { Villous blunting } \\
\end{array}$ \\
\hline \multicolumn{3}{|l|}{ Slow-turnover tissues } \\
\hline Lung & $\begin{array}{ll}\text { - } & \text { Premature-onset emphysema } \\
\text { - } & \text { Idiopathic pulmonary fibrosis } \\
& 12\end{array}$ & Emphysema with cigarette smoke ${ }^{99}$ \\
\hline Liver & Cryptogenic liver fibrosis-cirrhosis ${ }^{13,74}$ & Fibrotic fatty liver changes after injury ${ }^{102}$ \\
\hline Bone & $\begin{array}{ll}\text { - } & \text { Osteoporosis } \\
\text { - } & \text { Avascular necrosis } \\
58\end{array}$ & Decreased threshold for osteoporosis in $W r n$-deficient mice ${ }^{107}$ \\
\hline Endocrine & Uncertain & $\begin{array}{l}\text { - Impaired glucose tolerance owing to defective } \\
\text { insulin secretion }{ }^{97} \\
\text { - Decreased threshold for apoptosis with } \\
\text { endoplasmic reticulum stress in } \beta \text {-cells }{ }^{97} \\
\text { - Acquired insulin resistance with a high-fat diet }{ }^{108}\end{array}$ \\
\hline Cardiac muscle & & Dilated cardiomyopathy 100 \\
\hline Skeletal muscle & & Decreased threshold for Duchenne myopathy ${ }^{105}$ \\
\hline \multicolumn{3}{|l|}{ Cancer } \\
\hline Multiple tissue types & $\begin{array}{l}\text { - } \\
\text { Epithelial cancers (skin and other) })^{75} \\
\text { Haematological malignancies (MDS and } \\
\text { AML) }\end{array}$ & Gastrointestinal microadenoma $^{36}$ \\
\hline
\end{tabular}

AML, acute myeloid leukaemia; ER, endoplasmic reticulum; HSC, haematopoietic stem cell; MDS, myelodysplastic syndrome; NK, natural killer; Wrn, Werner syndrome ATP-dependent helicase. 